\title{
Effect of siRNA-induced silencing of cellular prion protein on tyrosine hydroxylase expression in the substantia nigra of a rat model of Parkinson's disease
}

\author{
X. Wang ${ }^{1 *}$, H.A. Yang ${ }^{2 *}$, X.N. Wang ${ }^{3}$ and Y.F. Du ${ }^{1}$ \\ ${ }^{1}$ Department of Neurology, \\ Shandong Provincial Hospital Affiliated to Shandong University, \\ Jinan, Shandong, China \\ ${ }^{2}$ Department of Neurosurgery, \\ Shandong Provincial Hospital Affiliated to Shandong University, \\ Jinan, Shandong, China \\ ${ }^{3}$ Department of Rehabilitation, \\ Shandong Traffic Hospital, Jinan, Shandong, China \\ *These authors contributed equally to this study. \\ Corresponding author: Y.F. Du \\ E-mail: yifeng96yf@sina.com \\ Genet. Mol. Res. 15 (2): gmr.15027406 \\ Received August 10, 2015 \\ Accepted December 7, 2015 \\ Published May 6, 2016 \\ DOI http://dx.doi.org/10.4238/gmr.15027406
}

\begin{abstract}
The most significant pathological feature of Parkinson's disease $(\mathrm{PD})$ is the progressive degeneration of dopaminergic (DA) neurons in the substantia nigra. Currently, available treatments for PD cannot prevent the loss of DA neurons. Tyrosine hydroxylase (TH) expressed in substantia nigra neurons catalyzes the conversion of tyrosine to L-3,4-dihydroxyphenylalanine (L-DOPA), which is the rate-limiting step of DA biosynthesis. Major reasons for PD occurrence include decreased TH activity in the substantia nigra and secondary DA suppression. Decreased TH activity and the resulting suppression
\end{abstract}


of DA synthesis (or neurotransmission) in the substantia nigra are key factors underlying the development of PD. Cellular prion protein (PRP) is a membrane glycoprotein expressed in the central nervous system. Although the sequence of PRP is highly conserved, its physiological function is unclear. The purpose of this study was to investigate the effect of PRP-targeted small interfering RNA (siRNA) on TH expression in a rat model of $\mathrm{PD}$. Thirty male Wistar rats were injected with 6-hydroxydopamine (6-OHDA) to generate a model of PD. The rats then received injections of PRP-siRNA or nonsense siRNA in the lateral ventricles. Substantia nigra samples were collected for quantification of PRP and TH expression using real-time polymerase chain reaction and western blotting. PRP-siRNA decreased PRP expression in the substantia nigra. TH expression was decreased in PD model rats but was increased after PRP silencing. We conclude that PRP-siRNA may increase TH expression in vivo and may therefore exert protective effects on neurons in a model of PD.

Key words: Parkinson's disease; Substantia nigra; Tyrosine hydroxylase; Cellular prion protein; Small interfering RNA

\section{INTRODUCTION}

The most significant pathological alteration associated with Parkinson's disease (PD) is the progressive degeneration of dopaminergic (DA) neurons in the substantia nigra. Further activation of D1 and D2 dopamine receptors leads to increased inhibition of the thalamus-cortex and subsequent motor dysfunction (Martin et al., 2011; Exner et al., 2012). Currently, available treatments for PD cannot prevent or reverse the loss of DA neurons (Duty and Jenner, 2011). Recent in vitro and animal studies of cell growth factors such as acidic fibroblast growth factor have found that these molecules induce severe side effects including fibrosis or even tumor formation, making them unsuitable for clinical trials (Staropoli et al., 2003; Jiang et al., 2004).

In substantia nigra neurons, tyrosine hydroxylase (TH) catalyzes the synthesis of L-3,4-dihydroxyphenylalanine (L-DOPA) from tyrosine, which is the rate-limiting step in DA biosynthesis. Thus, TH plays a crucial role in PD pathogenesis (Imai et al., 2000, 2001). Previous studies have demonstrated significant decreases in the expression level and activity of TH in the substantia nigra and striatum of PD patients and animal models of PD (Imai et al., 2001; Yang et al., 2003). Therefore, altered TH expression and function in the substantia nigra are important factors governing the pathogenesis of $\mathrm{PD}$.

Cellular prion protein (PRP) is a membrane glycoprotein with a highly conserved sequence. PRP is expressed in various tissues and cell types in the human body, including central nervous system neurons and glia. Previous studies have revealed multiple important cellular functions of PRP, including the prevention of apoptosis and oxidative stress (Puckett et al., 1991; Pan et al., 1992; Hornshaw et al., 1995; Brown et al., 1997; Stöckel et al., 1998). In this study, we injected PRP-directed small interfering RNA (siRNA) into the right lateral ventricles of PD model rats in order to investigate its effect on TH expression in the substantia nigra. 


\section{MATERIAL AND METHODS}

\section{PD animal model and siRNA injections}

Thirty male Wistar rats (200-240 g) were purchased from the Laboratory Animal Center of Shandong University. Rats were anesthetized by ip injection of $3.5 \%$ chloral hydrate $(350 \mathrm{mg} / \mathrm{kg})$ and were fixed in a stereotaxic apparatus. Each rat was injected with 6-hydroxydopamine (6-OHDA; Sigma-Aldrich, St. Louis, MO, USA) (3 g/L, $6 \mu \mathrm{L}$, containing $0.2 \%$ ascorbic acid) in the substantia nigra pars compacta (coordinates relative to Bregma: posterior $5.2 \mathrm{~mm}$, depth $7.6 \mathrm{~mm}$, left lateral $1.8 \mathrm{~mm}$ ) and ventral tegmental area (coordinates relative to Bregma: posterior $5.6 \mathrm{~mm}$, depth $7.4 \mathrm{~mm}$, left lateral $0.9 \mathrm{~mm}$ ) according to previous study (Vercammen et al., 2006). The drug was injected at a rate of $0.5 \mu \mathrm{L} / \mathrm{min}$. The needle was left in place for $15 \mathrm{~min}$ after injection before being withdrawn at a speed of $1 \mathrm{~mm} / \mathrm{min}$ and the puncture site was covered with a gelatin sponge. To implant a cannula in the lateral ventricle, the skull was first drilled with the Bregma coordinates of the injection site until the dura was reached. A 9-gauge needle was then inserted to a depth of $1.5 \mathrm{~mm}$. The puncture site was sealed with dental cement.

Rats were randomly assigned to 3 groups of 10 animals each: a sham-injected group, a nonsense siRNA control group, and a PRP-siRNA group. PRP-siRNA or nonsense control siRNA (Santa Cruz Biotechnology, Dallas, TX, USA) was injected into the right lateral ventricle of rats 1 day after 6-OHDA injection and repeated every 5 days for one time. Nonsense control siRNA or PRP-siRNA was delivered via the implanted cannula. This study was preapproved by the Ethics Committee of Shandong University and was conducted in accordance with guidelines for the use of experimental animals as stipulated by local authorities.

\section{Real-time reverse-transcription polymerase chain reaction (RT-PCR)}

Five animals from each group were sacrificed through neck broken on day 20 after injection of siRNA, and equal volumes of the right middle ventral brain regions were collected. Total RNA was extracted from these samples using Trizol (Life Technologies, Carlsbad, CA, USA) following the manufacturer protocol. Real-time RT-PCR was performed using specific primers for PRP (forward primer: 5'-GUG CAC GAC UCAAUA TA-3'; reverse primer: 5'-TTC ACG UGC UGA CGC AG-3') and TH (forward primer: 5'-GGT GTG ATGGTG GGT ATG GGT-3'; reverse primer: 5'-CTG GGT CATCTT TTC ACG GTC-3') with the following steps: pre-denaturation at $94^{\circ} \mathrm{C}$ for $5 \mathrm{~min} ; 30$ cycles of denaturation at $94^{\circ} \mathrm{C}$ for $1 \mathrm{~min}$, annealing at $60^{\circ} \mathrm{C}$ for $1 \mathrm{~min}$, and elongation at $72^{\circ} \mathrm{C}$ for $3 \mathrm{~min}$; and elongation at $72^{\circ} \mathrm{C}$ for $5 \mathrm{~min}$. Relative mRNA levels were determined using the $2^{-\Delta \Delta \mathrm{Ct}}$ method.

\section{Western blotting}

Five animals from each group were sacrificed through neck broken on day 20 after injection of siRNA, and equal volumes of right middle ventral tissue were collected. After ultrasonic homogenization of the samples, total protein was extracted using an extraction kit (Thermo Fisher Scientific, Waltham, MA, USA) and stored at $-20^{\circ} \mathrm{C}$. Proteins were separated by SDS-PAGE and transferred to PVDF membrane. After blocking, the membrane was 
incubated overnight with anti-PRP (Santa Cruz) at 1:2000 dilutions. After secondary antibody incubation for $1 \mathrm{~h}$ at room temperature and visualization by enhanced chemiluminescence, the image was analyzed using the KONTRON Image Based Analysis System 2.0 (Zeiss, Oberkochen, Germany).

\section{Statistical analysis}

The SPSS 15.0 software was used to analyze data, which are reported as means \pm standard deviations (SD). The Student $t$-test was used for comparison between groups. Analysis of variance (ANOVA) and the post hoc q-test were used to compare means across multiple groups. Statistical significance was defined as $\mathrm{P} \leq 0.05$.

\section{RESULTS}

\section{PRP gene expression}

Twenty days after siRNA injection, animals in the PRP-siRNA group had significantly reduced PRP mRNA levels compared to the sham-injected group or nonsense siRNA control groups $(\mathrm{P} \leq 0.05$; Figure 1$)$.

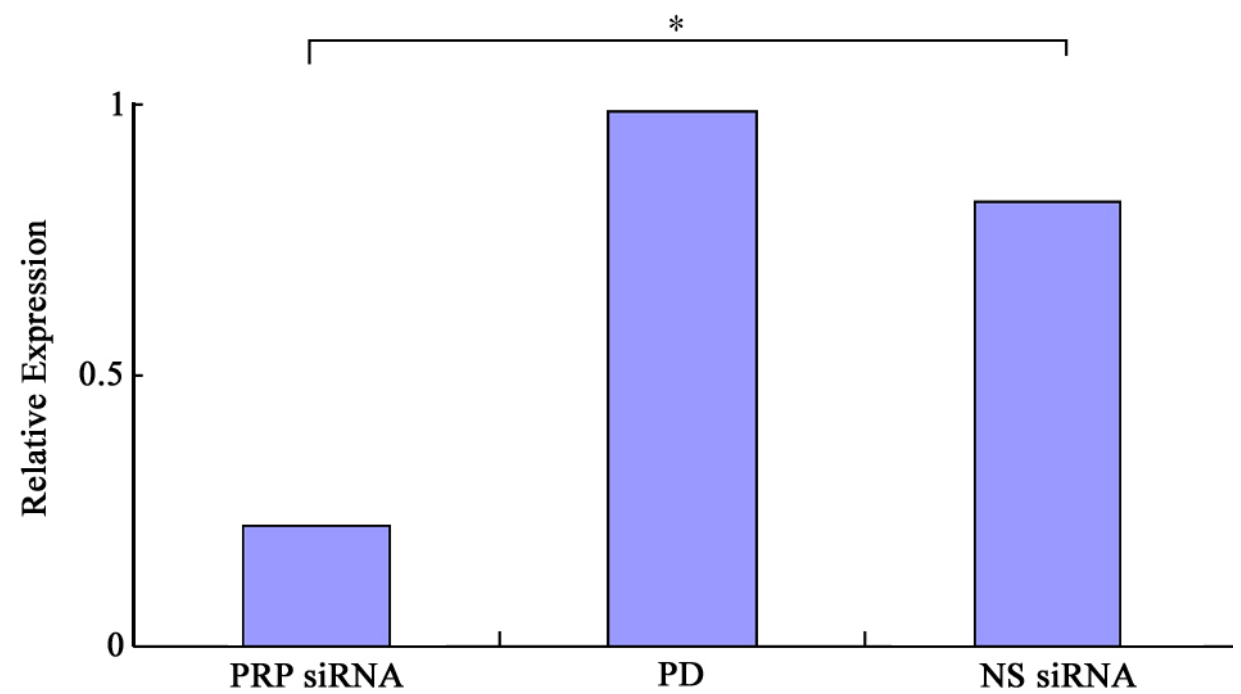

Figure 1. Relative expression of cellular prion protein (PRP) mRNA. siRNA: small interfering RNA; PD: Parkinson's disease; NS siRNA: nonsense siRNA control group. $* \mathrm{P} \leq 0.05, \mathrm{~N}=5$.

\section{PRP protein expression level}

Consistent with the reduced level of PRP mRNA, PRP protein levels were significantly decreased by PRP-siRNA treatment 20 days after injection $(\mathrm{P} \leq 0.05$; Figure 2$)$. 


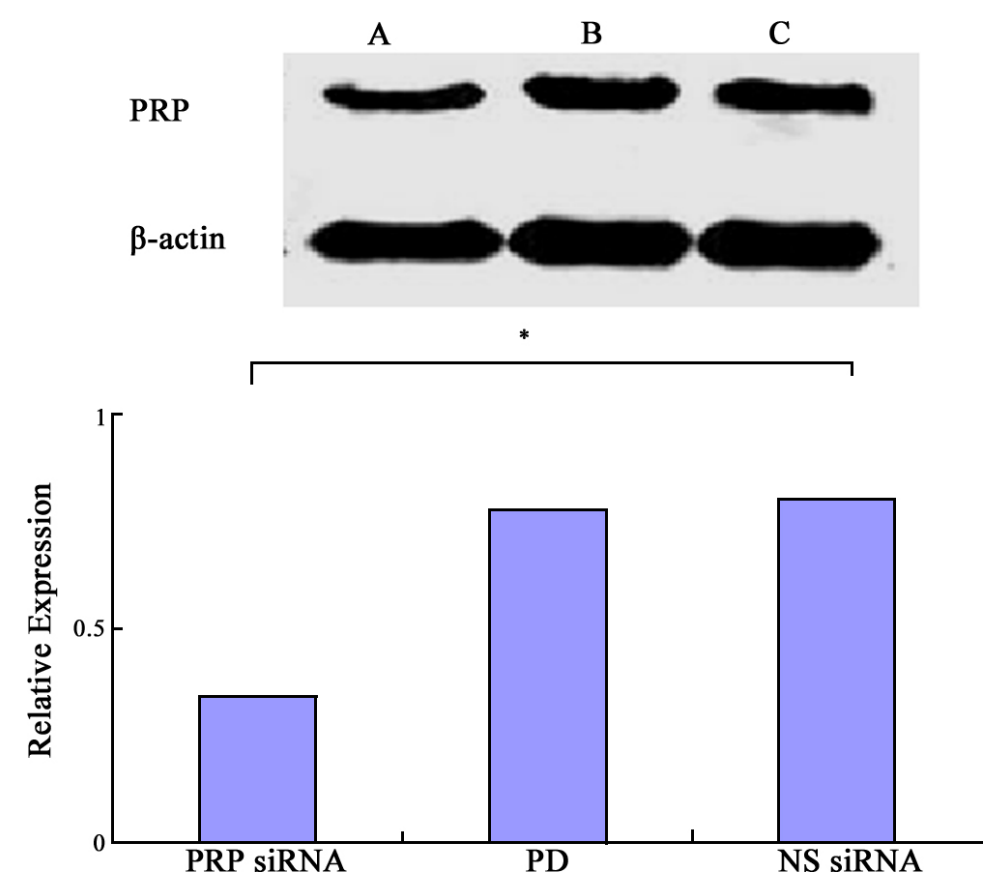

Figure 2. PRP protein levels. Upper panel: representative western blot image. A, PRP-siRNA group; B, shaminjected group; $\mathrm{C}$, nonsense siRNA control group. Lower panel: quantification of western blotting results. $* \mathrm{P} \leq$ $0.05, \mathrm{~N}=5$. For abbreviations, see legend to Figure 1 .

\section{TH mRNA level}

Injection of PRP-siRNA significantly elevated TH mRNA levels in PD model rats (P $\leq 0.05$; Figure 3 ).

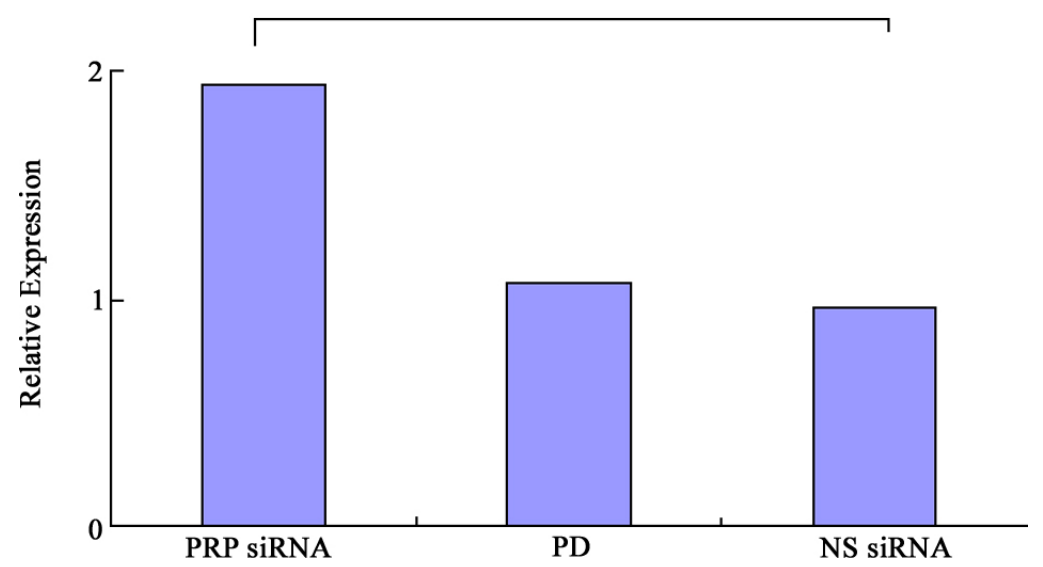

Figure 3. Relative expression of tyrosine hydroxylase $(\mathrm{TH}) \mathrm{mRNA}$. $* \mathrm{P} \leq 0.05, \mathrm{~N}=5$. For abbreviations, see legend to Figure 1. 


\section{DISCUSSION}

PD is commonly treated using DA-replacement therapy. However, L-DOPA has caused various side effects in clinical practice. Many potential neuroprotective agents have been tested in both animal models and human clinical trials; however, no conclusive results have been obtained. Thus, the identification of a neuroprotective agent is critical to the prevention and treatment of PD (Staropoli et al., 2003; Jiang et al., 2004; Duty and Jenner, 2011; Martin et al., 2011; Exner et al., 2012).

PRP is a membrane-anchored protein with a glycosyl-phosphatidylinositol anchor sequence, through which it can bind to membrane target sites for further surface anchorage. In the central nervous system, PRP is mainly expressed in neurons and microglia and is thus termed PRPC. Previous studies have implicated PRP in neuronal and glial development and maturation (Cashman et al., 1990; Puckett et al., 1991; Pan et al., 1992; Hornshaw et al., 1995; Brown et al., 1997; Stöckel et al., 1998; Antoine et al., 2000). PRPC and its related signaling pathways are also involved in neuronal differentiation and synaptic development. Furthermore, in vitro studies have demonstrated the role of PRPC in regulating the proliferation and differentiation of neural progenitor cells. The role of PRP in PD, however, has not been well studied (Dürig et al., 2000; Li et al., 2001).

siRNA inhibits gene expression through the formation of double-stranded RNA. It has been used in certain clinical trials, in which it suppresses target gene expression by binding with homologous mRNAs. Advantages of siRNA include high specificity, as siRNA binds to homologous mRNAs once it has entered the host cell without interfering with the expression and function of other genes. siRNA also has high efficacy because of the Dicer enzyme, which can amplify transfected siRNA to generate large amounts of double-stranded RNA in a short time for rapid gene silencing. Finally, siRNA is inheritable. Previous studies have investigated the dependence of siRNA efficacy on sequence length and the use of siRNA in high-throughput data sets. As a result, siRNA is now widely used in the diagnosis of neurodegenerative diseases (Soukup et al., 2002; Huang et al., 2008).

There are numerous animal models of PD. In this study, we used the classic unilateral 6-OHDA rat model of PD. This model has the characteristic feature of morphine-induced single-direction head rotation (speed $>6$ rotations per minute). TH is an important molecule in the DA-mediated signaling pathway, which sends DA signals to the striatum. TH converts tyrosine to the DA precursor L-DOPA. Other features of TH include weak catalytic activity and high substrate specificity. Previous studies have reported significant decreases in THpositive neurons in PD animal models. In this study, we found significantly increased TH mRNA levels in PRP-siRNA-treated rats compared to nonsense siRNA-treated controls $(\mathrm{P} \leq$ 0.05). Preliminary studies have shown neuroprotective effects of PRP-siRNA in PD animal models. Future studies should attempt to replicate these results in other PD models.

It is well known that TH is the rate-limiting enzyme in DA synthesis, and that numbers of TH-positive cells are decreased in the substantia nigra of PD animal models. A direct protective effect of PRP-siRNA on TH-positive neurons has not been illustrated in this study. In summary, our study demonstrates that PRP-siRNA increases TH levels in the substantia nigra, which may exert protective effects on TH-positive neurons in animal models of PD. Further studies should be performed in other PD models to evaluate the potential use of PRPsiRNA in clinical practice. This study has thus provided new insights into mechanisms of neuronal protection in animal models of $\mathrm{PD}$. 


\section{Conflicts of interest}

The authors declare no conflict of interest.

\section{ACKNOWLEDGMENTS}

We thank the anonymous reviewers for reviewing this manuscript.

\section{REFERENCES}

Antoine N, Cesbron JY, Coumans B, Jolois O, et al. (2000). Differential expression of cellular prion protein on human blood and tonsil lymphocytes. Haematologica 85: 475-480.

Brown DR, Qin K, Herms JW, Madlung A, et al. (1997). The cellular prion protein binds copper in vivo. Nature 390: 684687. http://dx.doi.org/10.1038/37733

Cashman NR, Loertscher R, Nalbantoglu J, Shaw I, et al. (1990). Cellular isoform of the scrapie agent protein participates in lymphocyte activation. Cell 61: 185-192. http://dx.doi.org/10.1016/0092-8674(90)90225-4

Dürig J, Giese A, Schulz-Schaeffer W, Rosenthal C, et al. (2000). Differential constitutive and activation-dependent expression of prion protein in human peripheral blood leucocytes. Br.J.Haematol. 108: 488-495. http://dx.doi.org/10.1046/j.1365-2141.2000.01881.x

Duty S and Jenner P (2011). Animal models of Parkinson's disease: a source of novel treatments and clues to the cause of the disease. Br. J. Pharmacol. 164: 1357-1391. http://dx.doi.org/10.1111/j.1476-5381.2011.01426.x

Exner N, Lutz AK, Haass C and Winklhofer KF (2012). Mitochondrial dysfunction in Parkinson's disease: molecular mechanisms and pathophysiological consequences. EMBOJ. 31: 3038-3062. http://dx.doi.org/10.1038/emboj.2012.170

Hornshaw MP, McDermott JR, Candy JM and Lakey JH (1995). Copper binding to the N-terminal tandem repeat region of mammalian and avian prion protein: structural studies using synthetic peptides. Biochem. Biophys. Res. Commun. 214: 993-999. http://dx.doi.org/10.1006/bbrc.1995.2384

Huang C, Li M, Chen C and Yao Q (2008). Small interfering RNA therapy in cancer: mechanism, potential targets, and clinical applications. Expert Opin. Ther. Targets 12: 637-645. http://dx.doi.org/10.1517/14728222.12.5.637

Imai Y, Soda M and Takahashi R (2000). Parkin suppresses unfolded protein stress-induced cell death through its E3 ubiquitin-protein ligase activity. J. Biol. Chem. 275: 35661-35664. http://dx.doi.org/10.1074/jbc.C000447200

Imai Y, Soda M, Inoue H, Hattori N, et al. (2001). An unfolded putative transmembrane polypeptide, which can lead to endoplasmic reticulum stress, is a substrate of Parkin. Cell 105: 891-902. http://dx.doi.org/10.1016/S0092-8674(01)00407-X

Jiang H, Ren Y, Zhao J and Feng J (2004). Parkin protects human dopaminergic neuroblastoma cells against dopamineinduced apoptosis. Hum. Mol. Genet. 13: 1745-1754. http://dx.doi.org/10.1093/hmg/ddh180

Li R, Liu D, Zanusso G, Liu T, et al. (2001). The expression and potential function of cellular prion protein in human lymphocytes. Cell. Immunol. 207: 49-58. http://dx.doi.org/10.1006/cimm.2000.1751

Martin I, Dawson VL and Dawson TM (2011). Recent advances in the genetics of Parkinson's disease. Annu. Rev. Genomics Hum. Genet. 12: 301-325. http://dx.doi.org/10.1146/annurev-genom-082410-101440

Pan KM, Stahl N and Prusiner SB (1992). Purification and properties of the cellular prion protein from Syrian hamster brain. Protein Sci. 1: 1343-1352. http://dx.doi.org/10.1002/pro.5560011014

Puckett C, Concannon P, Casey C and Hood L (1991). Genomic structure of the human prion protein gene. Am. J. Hum. Genet. 49: 320-329.

Soukup J, Zauner A, Doppenberg EM, Menzel M, et al. (2002). The importance of brain temperature in patients after severe head injury: relationship to intracranial pressure, cerebral perfusion pressure, cerebral blood flow, and outcome. $J$. Neurotrauma 19: 559-571. http://dx.doi.org/10.1089/089771502753754046

Staropoli JF, McDermott C, Martinat C, Schulman B, et al. (2003). Parkin is a component of an SCF-like ubiquitin ligase complex and protects postmitotic neurons from kainate excitotoxicity. Neuron 37: 735-749. http://dx.doi. org/10.1016/S0896-6273(03)00084-9

Stöckel J, Safar J, Wallace AC, Cohen FE, et al. (1998). Prion protein selectively binds copper(II) ions. Biochemistry 37: 7185-7193. http://dx.doi.org/10.1021/bi972827k

Vercammen L, Van der Perren A, Vaudano E, Gijsbers R, et al. (2006). Parkin protects against neurotoxicity in the 6-hydroxydopamine rat model for Parkinson's disease. Mol. Ther. 14: 716-723. http://dx.doi.org/10.1016/j. ymthe.2006.06.009

Yang Y, Nishimura I, Imai Y, Takahashi R, et al. (2003). Parkin suppresses dopaminergic neuron-selective neurotoxicity induced by Pael-R in Drosophila. Neuron 37: 911-924. http://dx.doi.org/10.1016/S0896-6273(03)00143-0 